\title{
Fracture thresholds in osteoporosis: implications for hormone replacement treatment
}

\author{
P J Ryan, G M Blake, I Fogelman
}

\begin{abstract}
The bone mineral densities of the lumbar spine and femoral neck were determined by dual energy $x$ ray absorptiometry in 110 women aged 40-82 years (average 65 years) with spinal osteoporosis who had had at least one atraumatic vertebral compression fracture and in 1026 normal women aged 40-79 years (average 52 years). The women with osteoporosis showed a significant decrease in bone mineral density (BMD) at the lumbar spine and femoral neck compared with age matched normal women (sixth decade of life $-26 \%$ spine, $-23 \%$ femoral neck; seventh decade $-26 \%$ spine, $-16 \%$ femoral neck).

The fracture threshold, defined as the 90th centile of spinal BMD for women with osteoporosis, was $0.81 \mathrm{~g} / \mathrm{cm}^{2}$ at the lumbar spine and $0.656 \mathrm{~g} / \mathrm{cm}^{2}$ at the femoral neck. Five per cent of normal women aged $40-49$ years, $20 \%$ aged $50-59$ years, and $45 \%$ aged $60-69$ years had a BMD below this threshold. To maintain the bones of women above the fracture threshold until the age of 70 years about $50 \%$ of postmenopausal women need hormone replacement therapy. However, if the BMD is to be kept above the fracture threshold for a woman's lifetime, e.g. until the age of 80-90 years, then most women will need treatment, though for various lengths of time depending on their initial BMD. Measurements of BMD in postmenopausal women currently help in identifying the risk of osteoporotic fractures but in the lifetime assessment of risk in a single subject they may have a more important role in deciding the duration of hormone replacement therapy.
\end{abstract}

(Ann Rheum Dis 1992; 51: 1063-1065)

Bone mass cannot be substantially increased once osteoporotic fractures have occurred and at present the only viable approach to halting the growing epidemic of osteoporosis appears to be the prevention of bone loss. Consequently the measurement of bone mineral density (BMD) is being increasingly requested by doctors to assess a woman's risk of osteoporotic fracture. This part played by bone densitometry is supported by the recognition that bone mass is the most important determinant of bone strength with a relative risk of fracture increasing about twofold for every one standard deviation decrease in BMD. ${ }^{1}$ In addition many studies have now shown that a single postmenopausal measurement predicts the risk of future fracture. $^{2-4}$
Although many issues need to be resolved before widespread screening by BMD measurements can be generally recommended, ${ }^{5}$ an increasing number of women wish to have the best possible advice on long term hormone replacement therapy and request measurements of their BMD. They are supported by a Royal College of Physicians report recommending that women aged about 50 years should have their BMD measured and oestrogen offered to those below a specific threshold. ${ }^{6}$ At present there is no agreement on the threshold levels of BMD identifying which women should be treated nor the length of treatment. The aim of this study was to examine BMD measurements in women with osteoporosis and normal women and from these to determine guidelines for treatment.

\section{Methods}

Bone mineral density was measured using a dual energy $x$ ray absorptiometry system (Hologic QDR-1000) in 1026 normal white women aged 40-79 years (average age 52 years) referred for assessment of their risk of osteoporosis by doctors from London and the southeast of England. Women were not included as normal if they had a known secondary cause of osteoporosis, a menopause before the age of 40 , a history of secondary amenorrhoea, use of steroids or hormone replacement treatment, a history of fractured spine, wrist or femur, or osteopenia detected radiologically as the reason for their referral. Bone mineral density was also measured in 110 women aged 40-82 years (average age 65 years) referred to an osteoporosis clinic with radiological confirmation of at least one atraumatic vertebral collapse.

Measurements of BMD were made at the lumbar spine and neck of femur. The spinal value was calculated as an average of the BMD from $\mathrm{Ll}$ to $\mathrm{L} 4$ and the femoral neck value was derived from a region of interest identified by the QDR-1000 software as a $1.5 \mathrm{~cm}$ band adjacent to the greater trochanter. Long term precision errors, estimated with daily BMD measurements using an anthropomorphic spine phantom, were $0.38 \%$ and the in vivo precision by four repeated measurements on three normal subjects over two weeks gave a coefficient of variation of $1 \cdot 1 \%$ for the lumbar spine and $1 \cdot 2 \%$ for the neck of femur. Two repeated measurements on the same day on 49 subjects with osteoporotic vertebral collapse gave a coefficient of variation of $1.6 \%$ for the lumbar spine and $1 \cdot 2 \%$ for the femoral neck. Statistical analysis was performed using the paired $t$ test. 
Table 1 Mean $(S D)$ bone mineral density $(B M D)\left(\mathrm{g} / \mathrm{cm}^{2}\right)$ of spine and neck of femur in normal women and women with osteoporosis

\begin{tabular}{lll}
\hline Age range (years) & Spinal BMD & Femoral BMD \\
\hline $50-59$ (normal women $(\mathrm{n}=606))$ & $0.934(0 \cdot 167)$ & $0 \cdot 750(0 \cdot 145)$ \\
$50-59$ (women with osteoporosis $(\mathrm{n}=29))$ & $0 \cdot 691(0 \cdot 110)$ & $0.579(0 \cdot 091)$ \\
$60-69$ (normal women $(\mathrm{n}=109))$ & $0.838(0 \cdot 149)$ & $0.659(0 \cdot 136)$ \\
$60-69$ (women with osteoporosis $(\mathrm{n}=53))$ & $0.622(0 \cdot 163)$ & $0.556(0 \cdot 119)$ \\
\hline
\end{tabular}

Table 2 Numbers (per cent) of normal women with spinal or femoral neck bone mineral density (BMD) above the fracture thresholds

\begin{tabular}{lcc}
\hline Age (years) & \multicolumn{2}{c}{ No above fracture thresholds } \\
\cline { 2 - 3 } & \multicolumn{1}{c}{ Spine } & Femoral neck \\
\hline $40-44(\mathrm{n}=86)$ & $80(93)$ & $82(95)$ \\
$45-49(\mathrm{n}=237)$ & $216(91)$ & $207(87)$ \\
$50-54(\mathrm{n}=350)$ & $292(83)$ & $311(89)$ \\
$55-59(\mathrm{n}=246)$ & $171(69)$ & $184(75)$ \\
$60-64(\mathrm{n}=78)$ & $48(62)$ & $44(56)$ \\
$65-69(\mathrm{n}=29)$ & $16(55)$ & $15(52)$ \\
\hline
\end{tabular}

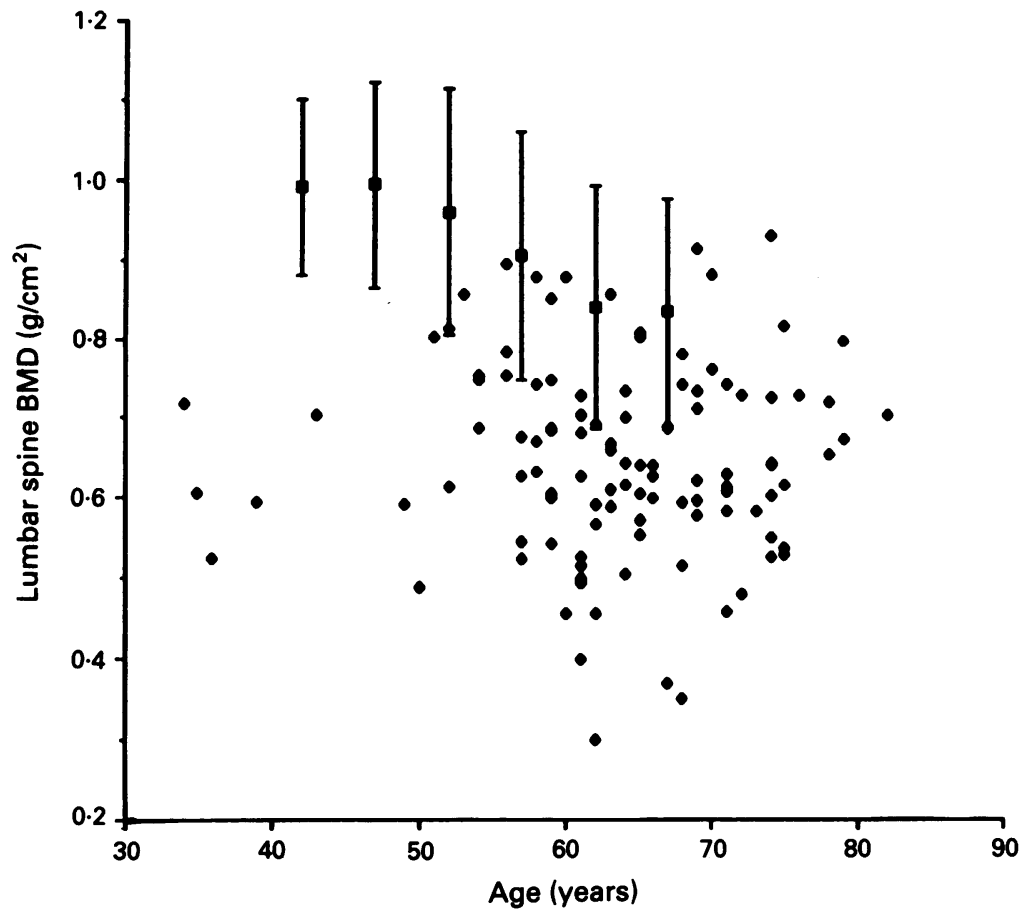

Lumbar spine bone mineral density (BMD) (mean (SD)) for 1026 normal women aged 40-70 years plotted versus age and superimposed on a scatter plot of lumbar spinal BMD versus age for 110 women with osteoporosis.
Results

Table 1 gives the BMD results for the spine and femur in normal women and women aged 50-69 years with osteoporosis. There were only two women with spinal fractures in their fifth decade of life and three normal women in their eighth decade preventing an extension of the age range for comparison of the two groups. Spinal BMD was significantly decreased in the group with osteoporosis $(p<0.001)$ by $-26 \%$ in women in the sixth and seventh decades. Femoral neck BMD was also significantly decreased $(\mathrm{p}<0.001)$ by $-23 \%$ in the sixth decade and $-16 \%$ in the seventh decade.

A BMD fracture threshold has been defined as the 90th centile of BMD for the group with fractures. ${ }^{7}$ Using this definition the lumbar spine threshold was identified as $0.810 \mathrm{~g} / \mathrm{cm}^{2}$ and the femoral neck threshold as $0.656 \mathrm{~g} / \mathrm{cm}^{2}$ in the patients with osteoporosis.

The number and percentage of the 1026 normal women with spinal or femoral neck BMDs above the respective threshold values were calculated for five year age bands and are given in table 2 . It is clear that there is an overlap in the spinal BMD values for the normal and osteoporotic groups. The figure shows a plot of spinal BMD results versus age for the group with osteoporosis with the mean (SD) values for the normal women superimposed.

We examined further the BMD of normal postmenopausal women with the same age of menopause, where known, but different chronological ages (tables 3 and 4). The average BMD weighted by age decreased by 0.006 $\mathrm{g} / \mathrm{cm}^{2} /$ year at the lumbar spine and femoral neck between six and 10 years (average eight years) and $11-15$ years (average 13 years) after menopause. Assuming that bone mass decreases at the same rate after 11-15 years postmenopause as between six and 10 and 11 and 15 years, the average lumbar spine BMD would reach the spinal fracture threshold 18 years and the femoral neck threshold 15 years after the menopause.

Table 3 Mean spinal bone mineral density $(B M D)\left(\mathrm{g} / \mathrm{cm}^{2}\right)$ of women with same age at menopause but different chronological ages

\begin{tabular}{|c|c|c|c|c|c|c|}
\hline \multirow[t]{3}{*}{ Age (years) } & \multicolumn{6}{|c|}{ Years from menopause } \\
\hline & \multicolumn{2}{|l|}{$1-5$ years } & \multicolumn{2}{|l|}{$6-10$ years } & \multicolumn{2}{|l|}{$11-15$ years } \\
\hline & No of women & Mean BMD & No of women & Mean BMD & No of women & Mean $B M D$ \\
\hline $\begin{array}{l}45-49 \\
50-54 \\
55-59 \\
60-64 \\
65-69\end{array}$ & $\begin{array}{r}42 \\
159 \\
107 \\
-\end{array}$ & $\begin{array}{l}0.939 \\
0.945 \\
0.930 \\
=\end{array}$ & $\begin{array}{l}-31 \\
62 \\
22 \\
-\end{array}$ & $\begin{array}{l}-\overline{0.879} \\
0.862 \\
0.906 \\
-\end{array}$ & $\begin{array}{r}- \\
\overline{25} \\
28 \\
7\end{array}$ & $\begin{array}{l}- \\
\overline{0} \cdot 857 \\
0.822 \\
0.848\end{array}$ \\
\hline
\end{tabular}

Table 4 Femoral neck bone mineral density $(B M D)\left(\mathrm{g} / \mathrm{cm}^{2}\right)$ of women with same age at menopause but different chronological ages

\begin{tabular}{|c|c|c|c|c|c|c|}
\hline \multirow[t]{3}{*}{ Age (years) } & \multicolumn{6}{|c|}{ Years from menopause } \\
\hline & \multicolumn{2}{|l|}{$1-5$ years } & \multicolumn{2}{|l|}{$6-10$ years } & \multicolumn{2}{|l|}{$11-15$ years } \\
\hline & No of women & Mean BMD & No of women & Mean $B M I)$ & No of women & Mean BMD \\
\hline $\begin{array}{l}5-49 \\
50-54 \\
55-59 \\
60-64 \\
65-69\end{array}$ & $\begin{array}{r}42 \\
159 \\
107 \\
- \\
-\end{array}$ & $\begin{array}{l}0.731 \\
0.769 \\
0.751 \\
- \\
-\end{array}$ & $\begin{array}{l}-31 \\
62 \\
22 \\
-\end{array}$ & $\begin{array}{l}-\overline{0.718} \\
0.714 \\
0.710 \\
-\end{array}$ & $\begin{array}{r}- \\
\overline{25} \\
28 \\
7\end{array}$ & $\begin{array}{l}- \\
\overline{0} \\
0.701 \\
0.657 \\
0.673\end{array}$ \\
\hline
\end{tabular}




\section{Discussion}

Many doctors want to know a woman's risk of osteoporotic fracture with a view to helping them make an informed decision regarding the use of long term hormone replacement treatment. At present, however, there is no consensus regarding appropriate advice. A Royal College of Physicians report suggested that hormone replacement therapy should be offered to women who have a BMD below a certain specified cutoff value. ${ }^{6}$ As the lifetime risk of hip fracture is about one in three it might be reasonable to offer hormone replacement therapy to women with the lowest $30 \%$ BMD. Hip fractures do not only happen to those with the lowest $30 \%$ of $\mathrm{BMD}$, however, and furthermore the percentage of women who have spinal fractures, which can produce considerable morbidity, is probably higher than $30 \%$. $^{9}$

Another approach to the prevention of osteoporosis could be to maintain a woman's bone mass above the BMD threshold below which fractures occur. As can be seen from the figure, however, there is an overlap in the BMD of subjects with and without fractures and therefore no threshold can be chosen to completely separate the two groups. Furthermore whatever threshold is used increasing the threshold increases its sensitivity in identifying patients with fractures but at a cost of specificity, with a lower threshold having the reverse effect. A value of two standard deviations below young normal subjects has been proposed, ${ }^{10}$ however, though this is at about the 90th centile for spine and femoral neck BMD for crush fractures but at the upper 99th centile for femoral neck BMD for hip fractures. To overcome such regional differences it has been suggested that it should be defined with respect to a fixed upper axial BMD for the group of subjects with fractures, typically the 90 th $^{\text {centile. }}{ }^{7}$

Hormone replacement therapy is known to prevent loss of bone and to reduce fracture incidence in postmenopausal women. ${ }^{11} 12$ The phase of most rapid bone loss occurs in the first few years after the menopause and our data from women aged 40-69 years (tables 3 and 4) support those of others in showing that the age of menopause is a more important determinant of bone mass than chronological age. ${ }^{13-15}$ If bone mass is to be maintained at the highest level hormone replacement therapy should be introduced at the menopause, but it is not clear what percentage of subjects should be offered treatment. If we use the 90th centile of women with osteoporosis as the fracture threshold it is apparent (table 2) that less than $10 \%$ of normal women aged $40-44$ years fall below it but this increases to $25-30 \%$ by the age of 55-59 years and to about $50 \%$ by $65-69$ years. A case therefore exists to recommend hormone replacement therapy after the menopause to at least $50 \%$ of postmenopausal women. The data for BMD and years after the menopause (tables 3 and 4) show that the mean BMD will reach the fracture threshold about 18 years after menopause at the lumbar spine and after 15 years at the femoral neck. This also implies that to keep their BMD above the fracture threshold by the age of 70 years, at least $50 \%$ of postmenopausal women will have to be treated.

For women aged 70-90 years further bone loss will have occurred. Estimates for normal rates of bone loss in the elderly have varied between 0.2 and $1 \%,{ }^{7}{ }^{16}$ but any further bone loss will mean that most women will eventually have a BMD below the fracture threshold. Therefore if the aim of treatment is to maintain women above the fracture threshold for life, then most will need hormone replacement therapy. This implies that for most women BMD measurements should be performed to assess the duration of hormone replacement therapy. For assessment of the risk of osteoporosis and which subjects require hormone replacement therapy, however, BMD measurements, though remaining useful, will have a decreased part to play. On the basis of data expressed in this paper it should be possible to generate tables showing the necessary duration of hormone replacement therapy based on age at menopause or, if unknown, the chronological age, BMD and life expectancy. Serial measurements of BMD would allow refinements to be made to these recommendations.

1 Mazess $\mathbf{R}$ B. Bone density in diagnosis of osteoporosis: thresholds and breakpoints. Calcif Tissue Int 1987; 41: 117-8.

2 Hui $S$ L, Slemenda $C W$, Johnston C C Jr. Baseline measurement of bone mass predicts fracture in white women. Ann Intern Med 1989; 11: 355-61.

3 Cummings S R, Black D M, Nevitt M C, et al. Appendicular bone density and age predicts hip fractures in women. FAMA 1990; 263: 665-8.

4 Wasnich R D, Ross P D, Davis J W, Vogel J M. A comparison of single and multi-site BMC measurements for assessment of spine fracture probability. $\mathcal{J} \mathrm{Nucl} \mathrm{Med}$ 1989; 30: 1166-71.

5 Melton L J III, Eddy D M, Johnston C C. Screening for osteoporosis. Ann Intern Med 1990; 112: 516-28.

6 Fractured neck of femur. Prevention and management. Summary and recommendations of the Royal College of Physicians. F R Coll Physicians Lond 1989; 23: 8-12.

7 Riggs B L, Wahner H W, Seeman E, et al. Changes in bone mineral density of the proximal femur and spine with ageing. Differences between the postmenopausal and senile osteoporotic syndromes. $\mathcal{f}$ Clin Invest 1982; 70: 716-23.

8 Melton L J, Riggs B L. Epidemiology of age-related fractures. In: Avioli L V, ed. The osteoporotic syndrome. New York: Grune and Stratton, 1983: 45-72.

9 Nordin B E C, Peacock M, Aaron J, et al. Osteoporosis and osteomalacia. Clin Endocrinol Metab 1980; 9: 177-204.

10 Nordin B E C. The definition and diagnosis of osteoporosis. Calcif Tissue Int 1987; 40: 57-8.

11 Weiss N S, Ure C L, Ballard J H, Williams A R, Darling J R. Decreased risk of fractures of the hip and lower forearm with postmenopausal use of oestrogen. $N$ Engl f Med 1980; 303: 1195-8.

12 Keil D P, Felson D T, Anderson J J, Wilson P W F, Moskowvitz M A. Hip fracture and the use of oestrogens in postmenopausal women. The Framingham study. NEnglf Med 1987; 317: 1169-74.

13 Thomsen K, Godredsen A, Christiansen C. Is postmenopausal bone loss an age related phenomenon? Calcif Tissue Int 1986; 39: 123-7.

14 Nilas $\mathrm{L}$, Christiansen $\mathrm{C}$. Bone mass and its relationship to age and menopause. F Clin Endocrinol Metab 1987; 65: 697.

15 Hedlund $L$, Gallacher J C. The effect of age and menopause on bone mineral density of the proximal femur. f Bone Miner Res 1989; 4: 639_42.

16 Mazess R B, Barden H, Ettinger M, Schultz E. Bone density of the radius, spine and proximal femur in osteoporosis. $\mathcal{F}$ Bone Miner Res 1988; 3: 13-8. 